\title{
SISTEM PENDUKUNG KEPUTUSAN PENILAIAN KINERJA RESORT PENGELOLAAN TAMANNASIONAL BROMO TENGGER SEMERU MENGGUNAKAN METODE SIMPLE ADDITIVE WEIGHTING (SAW)
}

\author{
Faqih Fadlullah ${ }^{1}$, Ulla Delfana Rosiani ${ }^{2}$,Ely Setyo Astuti ${ }^{3}$
}

Program Studi Teknik Informatika, Jurusan Teknologi Informasi, Politeknik Negeri Malang. faqihfadlullah@gmail.com, ${ }^{2}$ ullarosi@gmail.com, ${ }^{3}$ ely.setyo.astuti@polinema.ac.id

\begin{abstract}
Abstrak
TNBTS telah menerapkan Resort Base Managememnt, yaitu sebuah sistem pengelolaan taman nasional yang berdasarkan pada pengelolaan resort PTN. Untuk meningkatkan kinerja dari setiap resort PTN perlu adanya suatu penilaian yang dilakukan secara berkala oleh jajaran pengelola TNBTS, namun penilaian yang dilakukan saat ini masih dilakukan secara manual dan menggunakan pandangan individu, sehingga penilaian yang dilakukan tidak dapat terukur dengan baik.

Oleh karena itu dibuatlah Sistem Pendukung Keputusan Penilaian Kinerja Resort Pengelolaan Taman Nasional Bromo Tengger Semeru Menggunakan Metode Simple Additive Weighting (SAW) yang diharapkan mampu melakukan penilaian secara terukur dan tepat. Metode SAW meupakan sebuah metode penjumlahan terbobot. Konsep metode SAW memberikan bobot kepada semua kriteria secara langsung kemudian melakukan perangkingan sehingga sangat cocok digunakan di kantor TNBTS. Hasil dari perhitungan SAW berupa perangkingan kinerja resort PTN, dimana rangking terendah akan dilihat oleh jajaran manajemen TNBTS untuk diambil tindakan lebih lanjut sebagai pengembangan resort kedepannya dan untuk rangking tertinggi akan diberikan reward oleh jajaran TNBTS.

Berdasarkan uji fungsional, aplikasi ini mampu digunakan untuk menilai kinerja resort PTN, hasil dari sistem ini telah diuji kecocokannya dengan perhitungan petugas TNBTS dengan tingkat kecocokan $75 \%$. Sehingga bisa dikatakan sistem ini telah dirancang dan dapat diimplementasikan.

Kata kunci : Sistem Pendukung Keputusan, SAW, Penilaian Kinerja Resort, TNBTS
\end{abstract}

\section{Pendahuluan}

\subsection{Latar Belakang}

Taman Nasional Bromo Tengger Semeru (TNBTS) ditetapkan dengan Keputusan Menteri Kehutanan Nomor : SK 178/Menhut-II/2005 tentang Penetapan Taman Nasional Bromo Tengger Semeru. Kawasan TNBTS mencakup area seluas $50.276,20$ ha yang terletak di 4 Kabupaten yaitu Pasuruan, Probolinggo, Lumajang dan Malang. Berdasarkan peraturan Menteri Kehutanan Nomor P 03/Menhut-II/2007 tentang Organisasi dan Tata Kerja Unit Pelaksana Teknis Taman Nasional, dan untuk meningkatkan efektifitas pengelolaan kawasan maka dapat ditetapkan resort pengelolaan taman nasional (PTN). Sejalan dengan hal tersebut, dalam pengelolaan TNBTS telah dibentuk 12 resort PTN. Struktur organisasi resort sekurangkurangnya terdiri dari 1 orang tenaga fungsional khusus yang bertugas sebagai kepala resort dengan dibantu oleh sekurang-kurangnya 1 orang Polhut, 1 orang tenaga fungsional $\mathrm{PEH}, 1$ orang tenaga fungsional umum dan 1 orang tenaga penyuluh kehutanan.

TNBTS sejak tahun 2007 telah menerapkan Resort Based Management (RBM), namun RBM ini mulai dirintis kembali pada tahun 2013, yaitu sebuah sistem pengelolaan taman nasional yang berdasarkan pada pengelolaan resort PTN. Dalam hal ini kebijakan diambil merupakan sistem bottom up, dengan berdasarkan pada kinerja resort. Untuk meningkatkan kinerja resort PTN perlu diadakan penilaian setiap bulannya dengan melaporkan progres pengelolaan, termasuk mengenai permasalahan yang terjadi dan penyelesaiannya. Laporan bulanan ini akan direkapitulasi secara tahunan untuk mengetahui seberapa baik kinerja resort PTN dan juga dapat mengetahui kekurangannya untuk pengembangan kedepannya. Namun penilaian yang dilakukan saat ini masih secara manual dan menggunakan pandangan individu, sehingga penilaian yang dilakukan tidak dapat terukur dengan baik.

Metode SAW merupakan sebuah metode penjumlahan terbobot dari rating kinerja pada setiap alternatif pada semua kriteria. Semua kriteria dari alternatif memiliki bobot yang nantinya akan dijumlahkan untuk memberi rangking suatu nilai. Untuk itu dibuatlah sebuah aplikasi "Sistem Pendukung Keputusan Penilaian Kinerja Resort Pengelolaan Taman Nasional Bromo Tengger Semeru (TNBTS) Menggunakan Metode Simple Additive Weighting (SAW)" yang diharapkan 
mampu melakukan penilaian secara terukur dan lebih tepat sasaran. Hasil dari perhitungan metode SAW berupa sebuah perangkingan kinerja 12 resort PTN, dimana rangking terendah akan dilihat oleh jajaran manajemen TNBTS untuk diambil tindakan lebih lanjut sebagai pengembangan resort PTN kedepannya.

\subsection{Rumusan Masalah}

Berdasarkan latar belakang yang tertera di atas, maka dapat ditarik rumusan masalah yaitu :

a. Bagaimana menentukan kriteria dan bobot dalam penilaian kinerja pada setiap Resort Pengelolaan Taman Nasional Bromo Tengger Semeru dengan menggunakan metode SAW ?

b. Bagaimana menentukan urutan rangking kinerja Resort Pengelolaan Taman Nasional Bromo Tengger Semeru?

\subsection{Batasan Masalah}

Dalam pembuatan Rancang Bangun Sistem Pendukung Keputusan Penilaian Kinerja Resort Pengelolaan Taman Nasional Bromo Tengger Semeru Menggunakan Metode SAW diperlukan beberapa batasan yang dibuat agar penulisan skripsi tidak menyimpang dari tujuan yang semula direncanakan, yaitu :

a. Merangking kinerja Resort Pengelolaan Taman Nasional Bromo Tengger Semeru.

b. Penilaian yang dilakukan mencakup 12 resort PTN yang ada di kawasan TNBTS.

c. Kriteria yang digunakan mengacu pada kebijakan penilaian yang dilakukan oleh jajaran pengelola TNBTS.

\section{Landasan Teori}

\subsection{Taman Nasional Bromo Tengger Semeru}

Berdasarkan Keputusan Menteri Kehutanan No.278/Kpts-VI/1997 tanggal 23 Mei 1997 menjadi $50.276,3 \mathrm{ha}$, terdiri dari daratan $(50.266,05 \mathrm{ha})$ dan perairan tawar (10,25 ha). Secara administratif, kawasan TNBTS terletak di 4 wilayah kabupaten, yaitu: Malang, Pasuruan, Probolinggo dan Lumajang. Selain memiliki bentang alam yang indah, TNBTS memiliki fungsi penting bagi perlindungan keanekaragaman hayati. Setidaknya, 1.025 jenis tumbuhan dan 158 jenis satwa terdapat di kawasan ini. TNBTS juga merupakan hulu DAS Brantas dan DAS Sampean yang menjadi sumber air bagi sebagian besar masyarakat di Provinsi Jawa Timur. Lebih jauh, kawasan ini merupakan rumah bagi Suku Tengger dengan kehidupan religi dan budayanya yang khas. Sejak 9 Juni 2015, kawasan TNBTS ditetapkan oleh UNESCO sebagai bagian dari kawasan Cagar Biosfer Bromo Tengger Semeru Arjuno (CB-BTSA). Bersama dengan kawasan tahura R Soerjo, kawasan TNBTS menjadi zona inti dari CB-BTSA. Secara administratif, kawasan CB-BTSA mencakup 6 wilayah kabupaten
(Malang, pasuruan, Probolinggo, Lumajang, Jombang dan Mojokerto) dan 4 wilayah kota (Malang, batu, pasuruan dan probolinggo). Dengan status ini, pengelolaan kawasan diarahkan lebih mengedepankan harmonisasi antara alam, manusia, budaya dan religi.

\subsection{Sistem Pendukung Keputusan (SPK)}

Sistem Pendukung Keputusan (SPK) atau Decision Support System (DSS) adalah sebuah sistem yang mampu memberikan kemampuan pemecahan masalah maupun kemampuan pengkomunikasian untuk masalah dengan kondisi semi terstruktur dan tak terstruktur. SPK bertujuan untuk menyediakan informasi, membimbing, memberikan prediksi serta mengarahkan kepada pengguna informasi agar dapat melakukan pengambilan keputusan dengan lebih baik.

\subsection{Metode Simpe Additive Weighting (SAW)}

Metode Simple Additive Weighting (SAW) sering juga dikenal istilah metode penjumlahan terbobot. Konsep dasar metode SAW adalah mencari penjumlahan terbobot dari rating kinerja pada setiap alternatif pada semua atribut. Metode SAW membutuhkan proses normalisasi matriks keputusan (X) ke suatu skala yang dapat diperbandingkan dengan semua rating alternatif yang ada. (Sumber

http://landasanteori.com/2015/10/metode-simpleadditive-weighting-saw.html? $\mathrm{m}=1$ )

Formula untuk melakukan normalisasi tersebut adalah sebagai berikut :

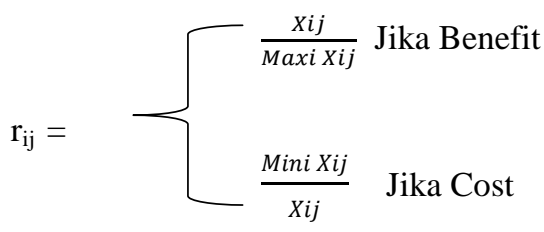

Dimana:

rij = rating kinerja ternormalisasi dari alternatif $\mathrm{Ai}(\mathrm{i}=, 2, \ldots, \mathrm{m})$

Maxi = nilai maksimum dari setiap baris dan kolom.

Mini = nilai minimum dari setiap baris dan kolom.

Xij = baris dan kolom dari matriks.

Nilai preferensi untuk setiap alternatif (Vi) diberikan sebagai:

$$
V_{i}=\sum_{j=1}^{n} W_{j} r_{i j}
$$

Dimana:

$\mathrm{Vi}=$ Nilai akhir dari alternatif 
$\mathrm{Wi}=$ Bobot yang telah ditentukan

rij $\quad=$ Normalisasi matriks.

Nilai Vi yang lebih besar mengindikasikan bahwa alternatif Ai lebih terpilih.

\section{Pembahasan}

Pada penelitian kali ini adalah dengan menggunakan metode Simple Additive Weighting (SAW). Adapun tahapan - tahapan yang dilakukan pada metode SAW adalah menetapkan masalah, kriteria, sub kriteria, dan alternatif pilihan

1. Menentukan kriteria - kriteria yang dijadikan acuan pengambilan keputusan. Melalui proses wawancara, didapatkan beberapa kriteria dan sub kriteria yang dapat dijadikan acuan dalam pengambilan keputusan. Kriteria dan sub kriteria yang dimaksud adalah

- SDM (C1)

○ Jumlah Polhut (SSDM1)

○ Jumlah penyuluh (SSDM2)

○ Jumlah PEH (SSDM3)

- Keanekaragaman hayati (C2)

- Jumlah wisata (C3)

- Jumlah sumber air (C4)

- Kondisi sarpras (C5)

2. Menentukan bobot pada setiap kriteria dan sub kriteria. Berdasarkan wawancara yang telah dilakukan dengan pihak

TNBTS didapatkan bobot kriteria sebagai berikut :

$$
\begin{array}{lll}
\text { - } & \text { SDM (C1) } & 0.3 \\
\text { ○ Jumlah Polhut (SSDM1) } & 0.35 \\
\text { ○ Jumlah penyuluh (SSDM2) } & 0.35 \\
\text { O Jumlah PEH (SSDM3) } & 0.3 \\
\text { - } & \text { Keanekaragaman hayati (C2) } & 0.2 \\
\text { - } & \text { Jumlah wisata (C3) } & 0.15 \\
\text { - } & \text { Jumlah sumber air (C4) } & 0.2 \\
\text { - } & \text { Kondisi sarpras (C5) } & 0.15
\end{array}
$$

3. Nilai Krip

Dalam penelitian ini selain menggunakan bobot, menggunakan nilai krip untuk menentukan nilai setiap kriteria. Masing - masing kriteria memiliki nilai krip sebagai berikut

Tabel 3.1 Nilai krip 1-5

\begin{tabular}{|c|c|}
\hline 1 & 20 \\
\hline 2 & 40 \\
\hline 3 & 60 \\
\hline 4 & 80 \\
\hline 5 & 100 \\
\hline
\end{tabular}

Tabel 3.2 Nilai krip 1-10

\begin{tabular}{|c|c|}
\hline $1-2$ & 20 \\
\hline $3-4$ & 40 \\
\hline $5-6$ & 60 \\
\hline $7-9$ & 80 \\
\hline 10 & 100 \\
\hline
\end{tabular}

Tabel 3.3 Nilai krip 1-20

\begin{tabular}{|c|c|}
\hline $1-5$ & 20 \\
\hline $6-10$ & 40 \\
\hline $11-15$ & 60 \\
\hline $16-19$ & 80 \\
\hline 20 & 100 \\
\hline
\end{tabular}

Tabel 3.4 Nilai krip nilai kualitatif

\begin{tabular}{|c|c|}
\hline \multicolumn{2}{|c|}{ Sangat } \\
kurang
\end{tabular}

4. Alternatif :

- Pananjakan (A1)

- Ranupane (A2)

- Tengger Laut Pasir (A3)

- $\quad$ Gucialit (A4)

- Taman Satriyan (A5)

\section{Perhitungan SAW}

1. Berikut merupakan tabel data uji

Sebelum masuk pada tabel uji kriteria utama, berikut penjelasan untuk perhitungan sub kriteria untuk nilai kriteria utama yaitu dengan mengalikan nilai sub kriteria dengan bobot masing-masing kriteria kemudian setiap sub kriteria pada alternative dijumlahkan.

a. Tabel sub kriteria SDM

Tabel 3.5 Tabel Sub Kriteria SDM

\begin{tabular}{|c|c|c|c|}
\hline A/SSDM & SSDM1 & SSDM2 & SSDM3 \\
\hline A1 & 4 & 2 & 5 \\
\hline A2 & 2 & 3 & 3 \\
\hline A3 & 5 & 4 & 3 \\
\hline A4 & 1 & 5 & 3 \\
\hline A5 & 2 & 3 & 1 \\
\hline
\end{tabular}

b. Konversi kedalam nilai angka sesuai nilai krip

Tabel 3.6 Tabel Konversi nilai krip

\begin{tabular}{|c|c|c|c|}
\hline A/SSDM & SSDM1 & SSDM2 & SSDM3 \\
\hline A1 & 80 & 40 & 100 \\
\hline A2 & 40 & 60 & 60 \\
\hline A3 & 100 & 80 & 60 \\
\hline A4 & 20 & 100 & 60 \\
\hline A5 & 40 & 60 & 20 \\
\hline Bobot & 0.35 & 0.35 & 0.3 \\
\hline \multicolumn{4}{|c|}{ perhitungan diatas }
\end{tabular}

didapatkan hasil sebagai berikut

TSDM1 untuk A1 adalah 72

TSDM2 untuk A2 adalah 53

TSDM3 untuk A3 adalah 81

TSDM4 untuk A4 adalah 60

TSDM5 untuk A5 adalah 41 
c. Tabel data uji

Tabel 3.7 Tabel Data Uji

\begin{tabular}{|l|l|l|l|l|l|}
\hline A/C & C1 & C2 & C3 & C4 & C5 \\
\hline A1 & TSDM1 & $6-10$ & 2 & 2 & Baik \\
\hline A2 & TSDM2 & $11-15$ & 4 & 2 & Kurang \\
\hline A3 & TSDM3 & $6-10$ & 3 & 3 & Kurang \\
\hline A4 & TSDM4 & $16-19$ & 5 & 1 & Baik \\
\hline A5 & TSDM5 & $1-5$ & 3 & 2 & Cukup \\
\hline
\end{tabular}

2. Dari tabel uji diatas, nilai huruf diganti dengan nilai angka sesuai dengan nilai krip, dan hasilnya adalah sebagai berikut

\begin{tabular}{|l|l|l|l|l|l|}
\hline $\mathbf{A} / \mathbf{C}$ & $\mathbf{C 1}$ & $\mathbf{C 2}$ & $\mathbf{C 3}$ & $\mathbf{C 4}$ & $\mathbf{C 5}$ \\
\hline A1 & 72 & 40 & 40 & 40 & 80 \\
\hline A2 & 53 & 60 & 80 & 40 & 40 \\
\hline A3 & 81 & 40 & 60 & 60 & 40 \\
\hline A4 & 60 & 80 & 100 & 20 & 80 \\
\hline A5 & 41 & 20 & 60 & 40 & 60 \\
\hline MAX & $\mathbf{8 1}$ & $\mathbf{8 0}$ & $\mathbf{1 0 0}$ & $\mathbf{6 0}$ & $\mathbf{8 0}$ \\
\hline MIN & $\mathbf{4 1}$ & $\mathbf{2 0}$ & $\mathbf{4 0}$ & $\mathbf{2 0}$ & $\mathbf{4 0}$ \\
\hline Bobot & 0.3 & 0.2 & 0.15 & 0.2 & 0.15 \\
\hline
\end{tabular}

Tabel 3.8 Tabel Perkalian Normalisasi

3. Masing - masing kriteria pada tabel diatas menggunakan atribut benefit karena kita akan mencari nilai tertinggi yang bisa menghasilkan nilai value teritinggi. Sedangkan untuk mencari nilai terendah agar bisa menghasilkan value tertinggi menggunakan atribut cost. Untuk memperoleh hasil normalisasi pada pengujian menggunakan atribut benefit, digunakan rumus sebagai berikut

$$
r i j=\frac{x i j}{\text { Maxi xij }}
$$

4. Hasil dari rumus diatas adalah

$$
\begin{aligned}
& R 11=\frac{72}{\max (72 ; 53 ; 81 ; 60 ; 41)}=0,8 \\
& R 12=\frac{53}{\max (72 ; 53 ; 81 ; 60 ; 41)}=0.65 \\
& R 13=\frac{81}{\max (72 ; 53 ; 81 ; 60 ; 41)}=1 \\
& R 14=\frac{60}{\max (72 ; 53 ; 81 ; 60 ; 41)}=0.7 \\
& R 15=\frac{41}{\max (72 ; 53 ; 81 ; 60 ; 41)}=0.5 \\
& \quad \text { dihitung sampai selesai, hingga } \\
& \text { didapatkan matriks normalisasi sebagai } \\
& \text { berikut }
\end{aligned}
$$

$$
\left\{\begin{array}{lllll}
0.8 & 0.5 & 0,4 & 0.6 & 1 \\
0.65 & 0.75 & 0.8 & 0.6 & 0.5 \\
1 & 0.5 & 0.6 & 1 & 0.5 \\
0.7 & 1 & 1 & 0.3 & 1 \\
0.5 & 0.25 & 0.6 & 0.6 & 0.75
\end{array}\right\}
$$

Gambar 3.1 Matriks Normalisasi

5. Setelah diketahui hasil normalisasi proses berikutnya adalah mencari rangking pada setiap alternatif dengan rumus sebagai berikut.

$$
V_{i}=\sum_{j=1}^{n} W_{j} r_{i j}
$$

Dari rumus di atas bisa kita lihat bahwa setelah hasil normalisasi diketahui seperti pada matriks diatas, proses selanjutnya adalah mengalikan matriks tersebut dengan bobot masing masing kriteria seperti yang dituliskan pada rumus diatas. Hasil perkalian matriks normalisasi dan bobot kriteria di tunjukkan dibawah ini.

$$
\begin{gathered}
V 1=((0.8 \times 0.3)+(0.5 \times 0.2)+(0.4 \times 0.15) \\
+(0.6 \times 0.2)+(1 \times 0.15)) \\
=0.71 \\
V 2=((0.65 \times 0.3)+(0.75 \times 0.2)+(0.8 \times 0.15) \\
+(0.6 \times 0.2)+(0.5 \times 0.15)) \\
=0.67 \\
V 3=((1 \times 0.3)+(0.5 \times 0.2)+(0.6 \times 0.15) \\
+(1 \times 0.2)+(0.5 \times 0.15 /) \\
=0.76 \\
V 4=((0.7 \times 0.3)+(1 \times 0.2)+(1 \times 0.15) \\
+(0.3 \times 0.2)+(1 \times 0.15)) \\
=0.78 \\
V 5=((0.5 \times 0.3)+(0.25 \times 0.2)+(0.6 \times 0.15) \\
+(0.6 \times 0.2)+(0.75 \times 0.15)) \\
=0.53
\end{gathered}
$$

Hasil akhirnya adalah dengan menjumlahkan seperti yang tertera pada rumus di atas.

Tabel 3.9 Tabel Hasil Akhir

\begin{tabular}{|l|l|l|}
\hline A/C & Hasil & Rangking \\
\hline A4 & 0.78 & 1 \\
\hline A3 & 0.76 & 2 \\
\hline A1 & 0.71 & 3 \\
\hline A2 & 0.67 & 4 \\
\hline A5 & 0.53 & 5 \\
\hline
\end{tabular}

\section{Implementasi}

a. Halaman data Resort 


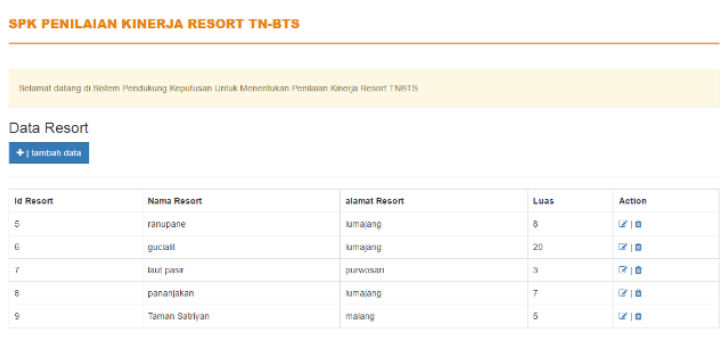

Gambar 4.1 Halaman Data Resort

b. Halaman data Kriteria

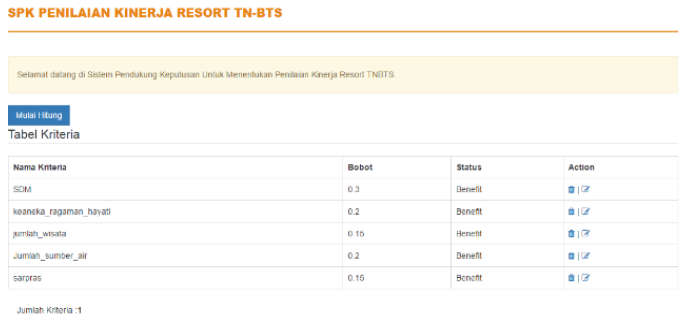

Gambar 4.2 Halaman Data Kriteria

c. Halaman data Periode Penilaian

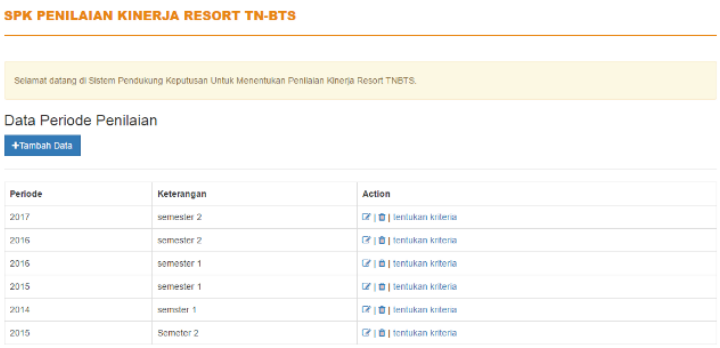

Gambar 4.3 Halaman Periode Penilian

d. Halaman Penilaian

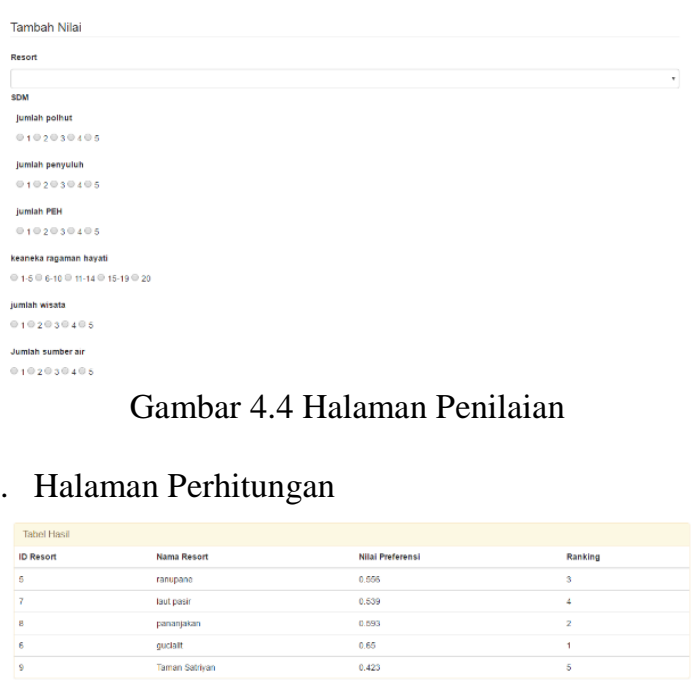

Gambar 4.5 Halaman Penilaian

\section{Kesimpulan Dan Saran}

\subsection{Kesimpulan}

Dari hasil penelitian tentang penerapan metode Simple Additive Weighting pada Sistem Pendukung Keputusan Penilaian Kinerja Resort Pengelolaan Taman Nasional Bromo Tengger Semeru Menggunakan Metode SAW dapat diambil kesimpulan bahwa :

1. Dengan adanya sistem ini mempermudah bidang teknis dan jajaran pengelola TNBTS dalam mengambil keputusan untuk pengembangan kinerja resort.

2. Aplikasi dapat menentukan kriteria dan bobot dalam penilaian kinerja resort PTN Bromo Tengger Semeru dengan menggunakan metode SAW.

3. Aplikasi dapat merangking kinerja resort PTN Bromo Tengger Semeru

4. Tingkat akurasi Sistem Pendukung Keputusan Penilaian Kinerja Resort Pengelolaan Taman Nasional Bromo Tengger Semeru 75\%

\subsection{Saran}

Berdasarkan dari pengujian Sistem Pendukung Keputusan Penilaian Kinerja Resort Pengelolaan Taman Nasional Bromo Tengger Semeru Menggunakan Metode SAW masih banyak kekurangan dan kelemahan, oleh karena itu adapun saran yang dapat penulis berikan adalah sebagai berikut :

1. Diharapkan pada pengembangan berikutnya sistem dapat dibangun dengan platform lain seperti berbasis desktop.

2. Diharapkan dilakukan penelitian selanjutnya dengan menggunakan metode lain.

\section{Daftar Pustaka}

BBTNBTS. 2013. Petunjuk Teknis Pengelolaan Taman Nasional Berbasis Resort di Balai Besar Taman Nasional Bromo Tengger Semeru. Malang

Sundari, Shinta Siti dan Taufik, Yopi Firman. 2014. Sistem Pendukung Keputusan Penerimaan Pegawai Baru Dengan Menggunakan Metode Simple Additive Weighting (SAW). STMIK Tasikmalaya. Jurnal Ilmiah Sisfotenika. Tasikmalaya

Utomo, Fandy Setyo dan Berlilana. 2010. Sistem Pendukung Keputusan Untuk Penilaian Kinerja Karyawan Dengan Metode Simple Additive Weighting. STMIK AMIKOM Purwokerto. Purwokerto

Metode Simple Additive Weighting (SAW) Langkah dan Kelebihan. 2015 [Online] Tersedia http://landasanteori.com/2015/10/metode- 
Volume 3, Edisi 1, November 2016

simple-additive-weighting-saw.html? $\mathrm{m}=1$

[08 Desember 2015]

Pengembangan Software dengan Metode Waterfall.

24 Maret 2013 [Online]. Tersedia :

http://etunas.com/web/pengembangan-

software-dengan-metode-waterfall.htm $\quad[11$

Desember 2015] 